\title{
Bindings of ChREBP and SREBP1, and Histone Acetylation around the Rat Liver Fatty Acid Synthase Gene Are Associated with Induction of the Gene during the Suckling-Weaning Transition
}

\author{
Saho Morishita ${ }^{1}$, Kazuki MochIZUKI ${ }^{2,3}$ and Toshinao GoDA ${ }^{2, *}$ \\ ${ }^{1}$ Department of Health and Nutritional Sciences, Faculty of Health Promotional Sciences, \\ Hamamatsu University, Kita-ku, Hamamatsu, Shizuoka 431-2102, Japan \\ ${ }^{2}$ Graduate School of Nutritional and Environmental Sciences, The University of Shizuoka, \\ Suruga-ku, Shizuoka, Shizuoka 422-8526, Japan \\ ${ }^{3}$ Department of Local Produce and Food Sciences, Faculty of Life and Environmental Sciences, \\ University of Yamanashi, Takeda, Kofu, Yamanashi 400-8510, Japan
}

(Received August 19, 2013)

\begin{abstract}
Summary It has been reported that the enzymic activity of fatty acid synthase (Fas) in rat liver increases during suckling-weaning transition. In this study, we investigated whether induction of the gene (Fasn) in the rat liver during the suckling-weaning transition is regulated by histone acetylation, and the nuclear transcription factors carbohydrate response element-binding protein (ChREBP) and sterol regulatory element-binding protein 1 (SREBP1). We observed that levels of Fas and Fasn increased during suckling-weaning transition. Binding levels of ChREBP and SREBP1 to upstream regions of Fasn increased during the suckling-weaning transition. Acetylation of histones H3 and H4 around Fasn increased during the transient period. Our results suggest that induction of liver Fasn during the suckling-weaning transition is closely associated with increased levels of ChREBP and SREBP1 binding, and acetylation of histones $\mathrm{H} 3$ and $\mathrm{H} 4$ around the gene.
\end{abstract}

Key Words FAS, ChREBP, SREBP1, histone acetylation, suckling-weaning transition

The suckling-weaning transition in laboratory rodents is accompanied by marked changes in dietary intake. During the suckling period, pups are fed milk, which is high in fat and low in carbohydrates. At the commencement of weaning (14-27 d post-partum) milk is progressively replaced by chow, which is high in carbohydrates and low in fat (1). This change in diet is followed by considerable hormonal modifications: an increase in plasma insulin concentration, and a decrease in plasma glucagon concentration (2). Carbohydrate intake and accompanying insulin secretion induce fatty acid synthesis in the liver and adipose tissues (3). It is supposed that dietary changes during the suckling-weaning transition would affect expression of genes related to fatty acid metabolism.

It is known that intake of a large amount of carbo-

\footnotetext{
*To whom correspondence should be addressed.

E-mail: gouda@u-shizuoka-ken.ac.jp

Abbreviations: CBP, CREB-binding protein; ChIP, chromatin immunoprecipitation; ChRE, carbohydrate response element; ChREBP, carbohydrate response element-binding protein; CT, cycle threshold; EDTA, ethylenediaminetetraacetic acid; ELISA, enzyme-linked immunosorbent assay; Fas, fatty acid synthase; HEPES, 4-(2-hydroxyethyl)-1-piperazineethanesulfonic acid; PBS, phosphate-buffered saline; RIPA, radio-immunoprecipitation assay; RT-PCR, quantitative reverse transcription-polymerase chain reaction; SDS, sodium dodecyl sulfate; SE, standard error of the mean; SRE, sterol response element; SREBP, sterol regulatory element-binding protein; SWI/SNF, switch/sucrose nonfermentable.
}

hydrates leads to enhanced activities for many liver enzymes necessary for converting glucose to fatty acids. Among the enzymes related to fatty acid synthesis, fatty acid synthase (Fas), which converts acetyl-coenzyme A to long-chain fatty acids, is a rate-controlling enzyme. Expression of Fas in the liver is higher in adult rats fed a high-carbohydrate diet compared with those fed a lowcarbohydrate diet (3). Additionally, Fas expression in hepatocytes was induced by media high in glucose, and insulin treatment (4). These results suggest that expression of the Fas gene (Fasn) is regulated by carbohydrate flow and/or insulin action in the liver. Regarding postnatal development in rats, it has already been reported that Fasn mRNA levels and activity of Fas are very low in the liver (5). The mRNA and enzyme activity levels are induced with increasing amounts of carbohydrate in the diet during weaning. When weaning rats are fed a high-fat diet, increases in Fasn mRNA and Fas activity are abolished (5). Thus, carbohydrate and insulin signals seem to be important for the induction of Fasn in the liver of rat pups during the suckling-weaning transition as well as in adult rats.

Many recent studies have demonstrated that expression of genes related to fatty acid synthesis, including Fasn, are regulated by transcriptional factors such as carbohydrate response element-binding protein (ChREBP) and sterol regulatory element-binding protein 1 (SREBP1) (6). Glucose signaling enhances ChREBP binding to the carbohydrate response element (ChRE) upstream of target genes by inducing dephos- 
phorylation of the ChREBP. This results in increased transcription of the target genes (7). SREBP1 is synthesized in a precursor form, which is located in the endoplasmic reticulum and the nuclear membrane. After the precursor is cleaved into the active form in an insulindependent manner, the mature SREBP1 enters into the nucleus and activates transcription of target genes by binding to the sterol response element (SRE) (8). Ciselements of ChREBP and SREBP1 are located in the promoter/enhancer region of Fasn $(9,10)$. It has already been reported that trans-activity of the upstream region of Fasn is enhanced by ChREBP (8) in hepatocytes, or by SREBP1 in adipocytes (11).

However, it is still unclear whether ChREBP and SREBP1 bind to the promoter/enhancer region of Fasn in vivo, and whether their binding is associated with induction of the gene during suckling-weaning transition. This could be examined using chromatin immunoprecipitation (ChIP) assays. Recent studies have demonstrated that an abrupt change in gene expression, which accompanies maturation and differentiation of cells, is regulated by histone modifications such as acetylation, methylation, and phosphorylation, as well as by transcriptional factors (12). In particular, the acetylation of histones $\mathrm{H} 3$ and $\mathrm{H} 4$ is thought to play a central role in the regulation of transcription. Hyperacetylation of histones $\mathrm{H} 3$ and $\mathrm{H} 4$ is associated with the euchromatin region of the genome (13). The subsequent acetylation of histones $\mathrm{H} 3$ and $\mathrm{H} 4$ is accompanied by binding of nuclear transcriptional factors, including ChREBP and SREBP1, to the promoter/enhancer region of genes. Such histone modifications have been shown to induce the binding of transcriptional machinery including coactivators, the SWI/SNF complex, transcriptional factors, and RNA polymerase II to their target genes (14, 15). Therefore, it is very likely that abrupt induction of liver Fasn during the suckling-weaning transition in rats is regulated by histone modifications and bindings of transcription factors such as ChREBP and SREBP1.

In this study, we examined whether the induction of the Fasn gene during the suckling-weaning transition in rats is regulated by a coordinated increase in binding of ChREBP and SREBP1, along with acetylation of histones $\mathrm{H} 3$ and $\mathrm{H} 4$.

\section{MATERIALS AND METHODS}

Animals. Pregnant Sprague-Dawley rats carrying fetuses at $10 \mathrm{~d}$ after gestation were obtained from Japan SLC, Inc. (Hamamatsu, Shizuoka, Japan). After the pups were born, they were kept with their mothers. Both mothers and pups were given free access to a standard laboratory chow diet consisting of $54.4 \%$ carbohydrates, $23.6 \%$ crude protein, and 5.3\% crude lipids (MF; Oriental Yeast Co., Ltd., Tokyo, Japan) throughout the experimental period. Rat pups were killed at 13, 20 and $27 \mathrm{~d}$ after birth. The experimental procedures used in the present study met the guidelines of the Animal Usage Committee of the University of Shizuoka.

Preparation of hepatic samples. The liver was washed with ice-cold $0.9 \% \mathrm{NaCl}$ solution and then divided into three parts for RNA extraction, immunoblotting, and ChIP assays. The tissues were immediately frozen in liquid nitrogen except for those for ChIP assays, and stored at $-80^{\circ} \mathrm{C}$.

Blood biochemical parameters. Serum in developing rats was collected by decapitation. Serum glucose and triacylglycerol concentrations were measured using commercial kits (Wako Pure Chemical Industries, Ltd., Osaka, Japan). Serum insulin concentration was measured using a Rat Insulin ELISA Kit (AKRIN010; Shibayagi, Gunma, Japan).

Quantitative reverse transcription-polymerase chain reaction ( $q R T-P C R)$. The hepatic tissue was homogenized in a solution consisting of $4 \mathrm{M}$ guanidine thiocyanate, $25 \mathrm{~mm}$ sodium citrate ( $\mathrm{pH} 7.5$ ), $0.5 \%$ sarcosyl, and 0.1 M 2-mercaptoethanol. Homogenates were immediately frozen in liquid nitrogen and stored at $-80^{\circ} \mathrm{C}$. Total RNA was extracted by the acidified guanidine thiocyanate method, as described by Chomczynski and Sacchi (16). The RNA samples $(2.5 \mu \mathrm{g})$ were reverse transcribed into cDNA using Super Script III reverse transcriptase $^{\mathrm{TM}}$ (Invitrogen, Carlsbad, CA) according to the manufacturer's instructions. PCR amplification was performed on a Light-Cycler 480 system (Roche Diagnostics, Mannheim, Germany). Reactions were carried out in a total volume of $10 \mu \mathrm{L}$ and contained gene-specific primers, cDNA, and SYBER Green Master I (Roche Diagnostics). The cycle threshold (CT) values for each gene detected by qRT-PCR were converted into signal intensities by the delta-delta CT method (17). We chose $18 \mathrm{~S}$ rRNA as the control gene. Specific primers were used to determine mRNA expression levels of genes encoding the following proteins: Fas (5'-GGA TGT CAA CAA GCC CAA GTA-3' and 5'-TTA CAG AGG AGA AGG CCA CAA-3'); ChREBP (5'-AAT CCC AGC CCC TAC ACC- $3^{\prime}$ and $5^{\prime}$-CTG GGA GGA GCC AAT GTG-3'); SREBP1 (5'-ACA AGA TTG TGG AGC TCA AG-3' and 5'-TGC GCA AGA CAG CAG ATT TA-3'); and 18S rRNA (5'-GGT GCA TGG CCG TTC TTA-3' and 5'-TCG TTC GTT ATC GGA ATT AAC C-3').

Immunoblotting. Frozen tissues were homogenized in radio-immunoprecipitation assay (RIPA) buffer ( $1 \%$ Nonidet P-40, 0.1\% SDS, 20 mM Tris-HCl pH 8.0, $5 \mathrm{~mm}$ EDTA, $150 \mathrm{~mm} \mathrm{NaCl}$ ) that contained phosphatase inhibitors $\left(1 \mathrm{mM} \mathrm{NaMoO}_{4}, 50 \mathrm{~mm} \mathrm{NaF}\right.$, and $1 \mathrm{~mm}$ $\mathrm{Na}_{3} \mathrm{VO}_{4}$ ) and protease inhibitors (1 tablet of complete Mini/10 mL; Roche Diagnostics). Lysates were centrifuged $\left(14,800 \times g, 30 \mathrm{~min}, 4^{\circ} \mathrm{C}\right)$ and total protein concentration in the supernatant was determined with the Lowry method (18). Hepatic extracts were separated by $10 \%$ SDS-PAGE and proteins in the gels were transferred to Immobilon membranes (Millipore, Billerica, MA). Membranes were blocked for $2 \mathrm{~h}$ in skim milk (3-10\%) made up in PBS (pH 7.4) supplemented with $0.05 \%$ Tween-20 (PBS-T) at room temperature. Membranes were then incubated at $4^{\circ} \mathrm{C}$ for at least $12 \mathrm{~h}$ with the following primary antibodies diluted in PBS-T containing 3-10\% skim milk: anti-FAS (Cell Signaling Technology, Inc., Danvers, MA), anti-ChREBP (Santa Cruz Biotechnology, Inc., Santa Cruz, CA), anti-SREBP1 
Table 1. Biochemical parameters in blood samples.

\begin{tabular}{lccc}
\hline & \multicolumn{3}{c}{ Days after birth } \\
\cline { 2 - 4 } & Day 13 & Day 20 & Day 27 \\
\hline Glucose (mg/dL) & $208 \pm 27^{\mathrm{ab}}$ & $260 \pm 9^{\mathrm{a}}$ & $187 \pm 10^{\mathrm{b}}$ \\
$\begin{array}{l}\text { Insulin (ng/dL) } \\
\text { Triacylglycerol } \\
(\mathrm{mg} / \mathrm{dL})\end{array}$ & $0.15 \pm 0.01^{\mathrm{a}}$ & $0.24 \pm 0.02^{\mathrm{b}}$ & $0.22 \pm 0.02^{\mathrm{b}}$ \\
& $146 \pm 19^{\mathrm{a}}$ & $121 \pm 16^{\mathrm{a}}$ & $66 \pm 4^{\mathrm{b}}$ \\
& & & \\
\hline
\end{tabular}

Data are expressed as mean \pm SE; $n=6-8$. Values not sharing a common letter are significantly different from one another $(p<0.05$, Tukey's multiple range test).

(Santa Cruz Biotechnology), and anti-TFIIB (Santa Cruz Biotechnology). After washing in PBS-T, membranes were incubated at $4^{\circ} \mathrm{C}$ for at least $12 \mathrm{~h}$ with anti-rabbit IgG conjugated to biotin (GE Healthcare, Little Chalfont, UK). Membranes were washed in PBS-T and incubated with horseradish peroxidase conjugated with anti-biotin (Cell Signaling, Tokyo, Japan). Positive signals were then detected by chemiluminescence (ECL Plus; GE Healthcare) using a LAS-3000 device (Fuji Film, Tokyo, Japan) according to the manufacturer's instructions. Relative signal intensities were evaluated with Multi Gauge (version 3.0; Fuji Film).

Chromatin immunoprecipitation (ChIP) assays. Fresh liver was homogenized in 4.5 mM HEPES buffer ( $\mathrm{pH} 8.0$ ) containing $1 \%$ formaldehyde, $9 \mathrm{mM} \mathrm{NaCl}, 0.09 \mathrm{~mm}$ EDTA, and $0.04 \mathrm{~mm}$ ethylene glycol tetraacetic acid, and incubated at $37^{\circ} \mathrm{C}$ for $30 \mathrm{~min}$. The reaction was terminated by treatment with $150 \mathrm{~mm}$ glycine at $37^{\circ} \mathrm{C}$ for $15 \mathrm{~min}$. Lysates were centrifuged at 1,200 $\times g$ for $15 \mathrm{~min}$ at $4^{\circ} \mathrm{C}$. After washing in fluorescence activated cell sorter (FACS) solution (PBS, 2\% bovine serum, 0.05\% $\mathrm{NaN}_{3}$ ), samples were sonicated in SDS lysis buffer containing $10 \mathrm{~mm}$ EDTA, 1\% SDS, and protease inhibitors (1 tablet of complete Mini/10 mL; Roche Diagnostics) in $50 \mathrm{mM}$ Tris-HCl, pH 8.0, to obtain 200-500 bp DNA fragments. The ChIP assay was performed as described previously (19), with the following antibodies: anti-ChREBP (Santa Cruz Biotechnology); anti-SREBP1 (Santa Cruz Biotechnology); anti-acetyl-histone H3 (Millipore); anti-acetylhistone H4 (Millipore); and control rabbit IgG. Precipitated DNA was analyzed by real-time PCR with primers complementary to sites in the promoter/enhancer and transcribed regions of the Fasn gene. ChIP results are expressed as a percent of the PCR signal for input DNA using the delta-delta CT method (17). The PCR primer sequences for amplification of various regions of the Fasn gene are listed below: FAS $-7,000 \mathrm{bp} \mathrm{(5'-CAT}$ GAT GTC TTG AGC AAG CTG-3' and 5'-ACA GCT GAG TGA GGC AAT GTT-3'); FAS-2,000 bp (5'-AGA AAG CCC ACG CTC AGT AAT- $3^{\prime}$ and 5'-AGA CAC AGC AAG AGT GAT CTG C-3'); FAS-1,000 bp (5'-ACT GCC CAT AAG GTT GGT CTT-3' and 5'-GGA CGG GAG ATG ATG AAA ACT-3'); FAS - 500 bp (5'-ATC ACC CTA TTG CCT AGC AAC G-3' and 5'TGC TCC ACA TCG AGA CCA AT-3'); FAS + 1,000 bp (5'-CCC ACT TCT GTT TGC AAG
A

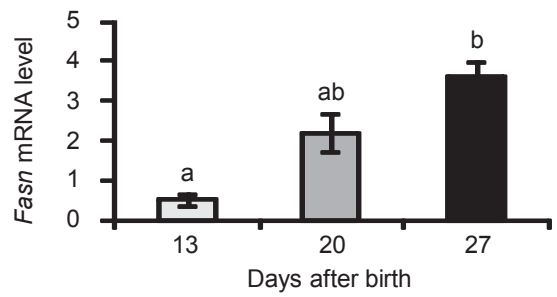

B
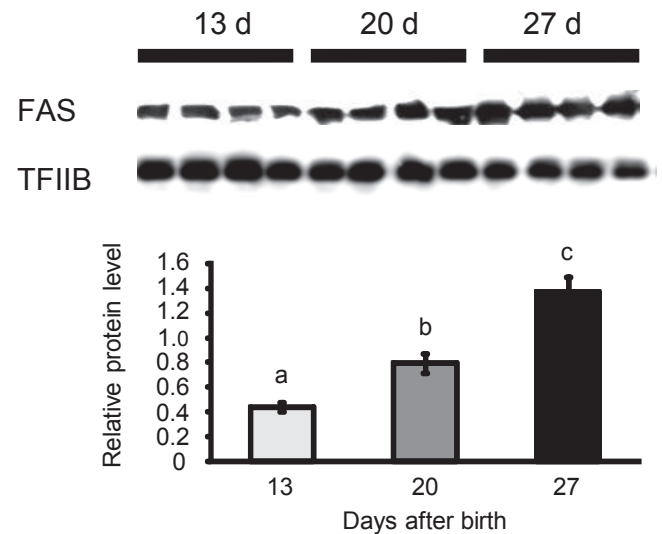

Fig. 1. Hepatic changes in Fasn mRNA (A) and Fas protein (B) levels during the suckling-weaning transition in rats. The mRNA levels were normalized to $18 \mathrm{~S}$ rRNA expression (A). The protein levels were normalized to TFIIB (B). Means \pm SE for 6-8 animals are shown. Values not sharing a common letter are significantly different from one another $(p<0.05$, Tukey's multiple range test).

TTC-3' and 5'-AAT CCC TTC CAG ACA CAT GAC-3'); FAS +2,000 bp (5'-TGA AGG ATC TGT CCA AGT TCG$3^{\prime}$ and 5'-CTC CGT CCA CAA TAG CTT CAT-3'); and FAS $+5,000 \mathrm{bp}\left(5^{\prime}\right.$-CCC AGT AAC CAT GTG TTT TGT C-3' and 5'-CCC AGT AAC CAT GTG TTT TGT C-3').

Statistical analysis. Group differences were analyzed by analysis of variance (ANOVA) followed by Tukey's multiple range test. A p-value less than 0.05 was considered significant.

\section{RESULTS}

\section{Changes in blood parameters during suckling-weaning}

Serum glucose levels were maximal at $20 \mathrm{~d}$ after birth, and decreased to a lower level at $27 \mathrm{~d}$ after birth. Serum insulin concentrations were higher at 20 and $27 \mathrm{~d}$ after birth than at $13 \mathrm{~d}$ after birth. Serum triacylglycerol concentration gradually decreased during weaning, and its level was significantly lower at $27 \mathrm{~d}$ after birth than at 13 and $20 \mathrm{~d}$ after birth (Table 1 ).

Hepatic changes in Fasn mRNA and Fas protein levels

The mRNA level for Fasn in the liver was low at $13 \mathrm{~d}$ after birth, and it gradually increased during the weaning period; Fasn mRNA levels at $27 \mathrm{~d}$ after birth were 6.6-fold higher than those at $13 \mathrm{~d}$ after birth (Fig. 1A). Similarly, the Fas protein level in the liver increased during the weaning period; Fas protein levels at $27 \mathrm{~d}$ after birth were 3.1-fold higher than those at $13 \mathrm{~d}$ after birth 

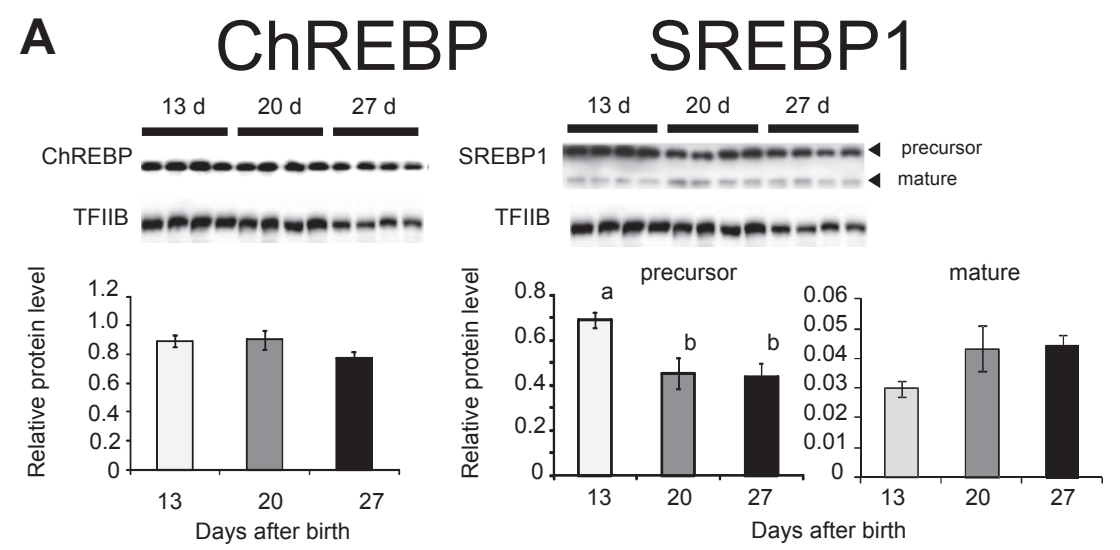

B

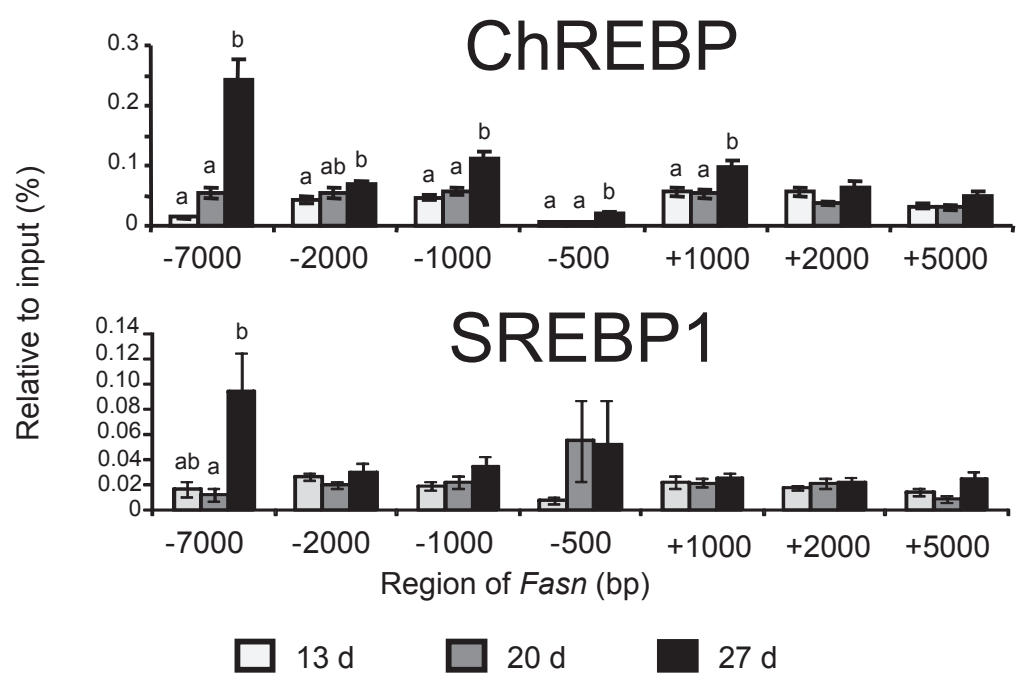

Fig. 2. Hepatic changes in levels of protein (A) and binding (B) for ChREBP and SREBP1 during the suckling-weaning transition in rats. The protein levels were normalized to TFIIB (A). Means \pm SE for 6-8 animals are shown. Values not sharing a common letter are significantly different from one another ( $p<0.05$, Tukey's multiple range test).

(Fig. 1B).

Hepatic changes in protein levels and in vivo binding of ChREBP and SREBP1 around Fasn gene

The ChREBP protein (93 kDa) levels were near constant during the suckling-weaning transition, with no significant differences observed among the levels at 13, 20 or $27 \mathrm{~d}$ after birth. The SREBP1 precursor protein (125 kDa) levels were significantly higher at $13 \mathrm{~d}$ after birth than those at 20 and $27 \mathrm{~d}$ after birth, whereas mature SREBP1 protein $(68 \mathrm{kDa})$ levels tended to be higher at 20 and $27 \mathrm{~d}$ after birth than those at $13 \mathrm{~d}$ after birth (Fig. 2A).

Next, we determined binding levels of ChREBP and SREBP1 around the Fasn gene using ChIP assays. The ChIP signals detected for control IgG were less than $0.03 \%$ per input for all regions of the Fasn gene (data not shown). The binding levels of ChREBP on the Fasn gene were significantly increased during the weaning period at the promoter/enhancer $(-7,000,-2,000$, $-1,000$ and $-500 \mathrm{bp})$ and transcribed $(+1,000 \mathrm{bp})$ regions. The binding levels of SREBP1 on the Fasn gene were significantly increased during the weaning period at an enhancer region ( $-7,000$ bp; Fig. 2B).
Hepatic changes in acetylation of histones $\mathrm{H} 3$ and $\mathrm{H} 4$ around Fasn gene

The acetylated histone H3 levels gradually increased during the weaning period on the transcribed regions $(+1,000,+2,000$ and $+5,000 \mathrm{bp})$; the levels at $27 \mathrm{~d}$ were significantly higher than those at $13 \mathrm{~d}$ after birth (Fig. 3). The acetylated histone H4 levels gradually increased during the weaning period on the promoter/ enhancer $(-7,000$ and $-2,000 \mathrm{bp})$ and transcribed regions $(+1,000,+2,000$ and $+5,000 \mathrm{bp})$ regions; the levels at $27 \mathrm{~d}$ were significantly higher than those at 13 and $20 \mathrm{~d}$ after birth (Fig. 3).

\section{DISCUSSION}

We have demonstrated in this study that both Fas protein and Fasn mRNA levels are increased in parallel in the liver during the suckling-weaning transition in rats, and that the rise in the Fasn mRNA levels are accompanied by increases in the bindings of ChREBP and SREBP1 to the upstream regions of the Fasn gene and the acetylation of histones $\mathrm{H} 3$ and $\mathrm{H} 4$ around the Fasn gene. The results presented here are consistent with those from previous studies which demonstrated that the expression of the Fasn gene is regulated by ChREBP 

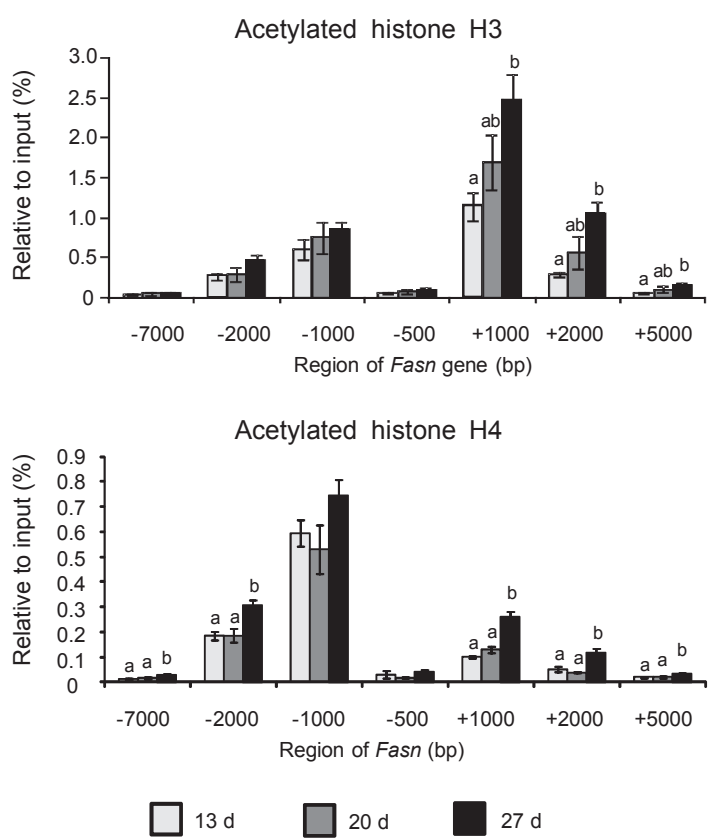

Fig. 3. Hepatic changes in acetylation of histones $\mathrm{H3}$ and $\mathrm{H} 4$ on the promoter/enhancer and transcribed regions of Fasn during the suckling-weaning transition in rats. Means \pm SE for 6-8 animals are shown. Values at the same region not sharing a common letter are significantly different from one another $(p<0.05$, Tukey's multiple range test).

and SREBP1, two major transcription factors which transduct carbohydrate and insulin signals, respectively, to carbohydrate- and/or insulin-dependent genes in the liver (6), and further suggested that induction of the Fasn gene during the suckling-weaning transition is regulated at the transcriptional level.

Previous studies showed that hepatic Fasn mRNA levels remained extremely low in ChREBP knockout mice fed a high-starch diet (60\% starch) compared with wildtype mice fed the same diet, despite increased glucose and insulin levels in the blood (20). Over-expression of SREBP1c, an isoform of SREBP1, was shown to induce the expression of the Fasn gene in hepatocytes (21). A previous in vitro study demonstrated, using gel shift assays, that ChREBP in the nuclear extract of rat liver bound to sequences of ChRE located in the promoter of Fasn (9). Luciferase assays have shown that a SREBP1 binding site in the Fasn promoter region is associated with its transactivation in the hepatic cell line HepG2 (10).

In this study, we have demonstrated using ChIP assays that the bindings of ChREBP and SREBP1 to the hepatic Fasn promoter/enhancer regions are elevated during the suckling-weaning transition. This is the first study to demonstrate that the bindings of these transcription factors to the promoter/enhancer region of the Fasn gene are modulated in vivo. Two isoforms of SREBP1 are known to be present (SREBP1a and SREBP1c), and the antibody we used in this study was able to detect both SREBP isoforms. Because previous studies have demonstrated that SREBP1c is predominantly expressed in the liver (22), we believe that SREBP1c is the dominant form that bound to the upstream region of the Fasn gene in this study.

It should be noted that ChREBP and active SREBP1 protein levels were not significantly changed during the suckling-weaning transition. It remains unknown which factors regulate the binding activity of these transcription factors. A recent study has reported that protein kinase A is involved in phosphorylation of SREBP1 in cultured hepatoma cells, and that the phosphorylation led to decreased binding of SRE (23). Another study has reported that SREBPs are negatively regulated by small ubiquitin-related modifier-1 (24). In addition, it has been reported that Ser196 of ChREBP is dephosphorylated by protein phosphatase $2 \mathrm{~A}$, which is activated by the glucose metabolite, xylulose-5-phosphate. The decrease in glucose concentration induces activation of cAMP-activated protein kinase, and it leads to enhanced phosphorylation of ChREBP at Ser196, which in turn results in reduced ChREBP trans-activity (25). Thus, it is very likely that posttranslational modifications of these transcription factors are altered during the suckling-weaning transition. Further studies should examine whether the posttranslational modifications of SREBP1 and ChREBP are related to the regulation of the Fasn gene in the liver during the suckling-weaning transition in rats.

In this study, we showed that ChREBP was bound around $-7,000 \mathrm{bp}$ of the rat liver Fasn gene and the binding was enhanced during the suckling-weaning transition. The result is consistent with a previous report showing that ChRE is located around the enhancer region (from $-7,214 \mathrm{bp}$ to $-7,190 \mathrm{bp}$ ) of the rat Fasn gene (26). The binding of SREBP1 at $-500 \mathrm{bp}$ of the rat Fasn gene observed in this study is likely associated with the binding of SREBP1 on the SRE, which was reported to be located around the promoter region (from - $151 \mathrm{bp}$ to $-142 \mathrm{bp}$ ) close to the $\mathrm{CpG}$ island and TATA box of the rat Fasn gene (27). In addition, we demonstrated in this study that the binding of SREBP1 at $-7,000$ bp was significantly increased from $20 \mathrm{~d}$ to $27 \mathrm{~d}$ after birth. It is still unclear whether SRE is located around $-7,000 \mathrm{bp}$ of the rat Fasn gene, because we were unable to find consensus sequences for the SRE (ATCACCCCAC) in these regions. Further studies should examine whether SRE is located around $-7,000$ bp of the rat Fasn gene by DNase I food printing and/or luciferase reporter assays, and whether ChREBP and/or SREBP1 play a crucial role in enhancing promoter activity of the Fasn gene as a component of transcription initiation factors in rat liver during the suckling-weaning transition period.

We found in this study that acetylation of histones $\mathrm{H} 3$ and $\mathrm{H} 4$ on the promoter/enhancer and/or transcribed regions of the Fasn gene were increased markedly from $13 \mathrm{~d}$ to $27 \mathrm{~d}$ after birth. This result suggests that acetylation of histones $\mathrm{H} 3$ and $\mathrm{H} 4$ is associated with increased Fasn gene expression in the liver of rats during development. SREBP1 binds specifically to the CREB-binding protein (CBP) and p300, both of which have histone acetyltransferase activity (28). CBP has 
been shown to enhance SREBP1-dependent transactivation in HeLa cells (28). ChREBP assembles the transcriptional complex containing CBP onto the prototypical glucose responsive L-type pyruvate kinase gene (29). Acetylation of histone N-terminal tail regions catalyzed by histone acetyltransferases leads to target gene induction, by controlling the accessibility of transcriptional machinery to chromatin (30). Thus, it is likely that not only binding of transcription factors, but also acetylation of histones, is involved in formation of transcriptional machinery onto the promoter region of the rat Fasn gene during the suckling-weaning transition. It should be investigated in future studies whether binding of transcriptional machinery to the promoter region of the rat Fasn gene is altered during the suckling-weaning transition period.

It should be noted that serum glucose levels were elevated at $20 \mathrm{~d}$, but decreased to a lower level at $27 \mathrm{~d}$ after birth, whereas serum insulin levels increased to higher levels at $20 \mathrm{~d}$ and $27 \mathrm{~d}$ after birth, and serum triacylglycerol levels were gradually decreased during the suckling-weaning transition period (Table 1). These changes in blood parameters were not apparently associated with the rises in mRNA levels of the Fasn gene and associated bindings of ChREBP, SREBP1 and acetylated histones around the Fasn gene. We speculate that the discrepancy is attributable to a change in the functional capability of the liver and adipose tissue during the suckling-weaning transition period (31), which plays a pivotal role in the uptake and utilization of glucose in an insulin-dependent manner. During the late-weaning period, i.e., between 20 and $27 \mathrm{~d}$ after birth, the reduction of serum glucose levels is likely caused by increased uptake of glucose in the liver as well as in the muscle and adipose tissue, along with maturation of insulin signal transduction system in these tissues.

In conclusion, we have demonstrated in this study in vivo that induction of the rat liver Fasn gene during the suckling-weaning transition period is associated with enhanced binding of ChREBP and SREBP1, and acetylation of histones $\mathrm{H} 3$ and $\mathrm{H} 4$ around the gene.

\section{Acknowledgments}

This work was supported by a Grant-in-Aid for Scientific Research (20590233) and for Young Scientists (22680054) from the Ministry of Education, Culture, Sports, Science, and Technology of Japan, the Global COE program, the Center of Excellence for Innovation in Human Health Sciences of the Ministry of Education, Science, Sports and Culture of Japan, and a grant from the Mishima Kaiun Memorial Foundation.

\section{REFERENCES}

1) Henning SJ. 1981. Postnatal development: coordination of feeding, digestion, and metabolism. Am J Physiol 241: G199-G214.

2) Girard J, Ferre P, Kervran A, Pegorier J, Assan R. 1977. Role of the insulin/glucagon ratio in the changes of hepatic metabolism during the development of the rat. In: Glucagon: Its Role in Physiology and Clinical Medicine (Foa PP, Bajaj JS, Foa NL, eds), p 563-581. Springer-
Verlag, New York.

3) Girard J, Perdereau D, Foufelle F, Prip-Buus C, Ferre P. 1994. Regulation of lipogenic enzyme gene expression by nutrients and hormones. FASEB J 8: 36-42.

4) Prip-Buus C, Perdereau D, Foufelle F, Maury J, Ferre P, Girard J. 1995. Induction of fatty-acid-synthase gene expression by glucose in primary culture of rat hepatocytes. Dependency upon glucokinase activity. Eur J Biochem 230: 309-315.

5) Perdereau D, Narkewicz M, Coupe C, Ferre P, Girard J. 1990. Hormonal control of specific gene expression in the rat liver during the suckling-weaning transition. Adv Enzyme Regul 30: 91-108.

6) Pegorier JP, Le May C, Girard J. 2004. Control of gene expression by fatty acids. J Nutr 134: 2444S-2449S.

7) Yamashita H, Takenoshita M, Sakurai M, Bruick RK, Henzel WJ, Shillinglaw W, Arnot D, Uyeda K. 2001. A glucose-responsive transcription factor that regulates carbohydrate metabolism in the liver. Proc Natl Acad Sci USA 98: 9116-9121.

8) Horton JD, Goldstein JL, Brown MS. 2002. SREBPs: activators of the complete program of cholesterol and fatty acid synthesis in the liver. J Clin Invest 109: 1125-1131.

9) Ishii S, Iizuka K, Miller BC, Uyeda K. 2004. Carbohydrate response element binding protein directly promotes lipogenic enzyme gene transcription. Proc Natl Acad Sci USA 101: 15597-15602.

10) Foufelle F, Ferre P. 2002. New perspectives in the regulation of hepatic glycolytic and lipogenic genes by insulin and glucose: a role for the transcription factor sterol regulatory element binding protein-1c. Biochem J 366: 377-391.

11) Kim JB, Sarraf P, Wright M, Yao KM, Mueller E, Solanes G, Lowell BB, Spiegelman BM. 1998. Nutritional and insulin regulation of fatty acid synthetase and leptin gene expression through ADD1/SREBP1. J Clin Invest 101: 1-9.

12) Schubeler D, MacAlpine DM, Scalzo D, Wirbelauer C, Kooperberg C, van Leeuwen F, Gottschling DE, O'Neill LP, Turner BM, Delrow J, Bell SP, Groudine M. 2004. The histone modification pattern of active genes revealed through genome-wide chromatin analysis of a higher eukaryote. Genes Dev 18: 1263-1271.

13) Roh TY, Cuddapah S, Zhao K. 2005. Active chromatin domains are defined by acetylation islands revealed by genome-wide mapping. Genes Dev 19: 542-552.

14) Soutoglou E, Talianidis I. 2002. Coordination of PIC assembly and chromatin remodeling during differentiation-induced gene activation. Science 295: 1901-1904.

15) Tou L, Liu Q, Shivdasani RA. 2004. Regulation of mammalian epithelial differentiation and intestine development by class I histone deacetylases. Mol Cell Biol 24: 3132-3139.

16) Chomczynski P, Sacchi N. 1987. Single-step method of RNA isolation by acid guanidinium thiocyanate-phenolchloroform extraction. Anal Biochem 162: 156-159.

17) Livak KJ, Schmittgen TD. 2001. Analysis of relative gene expression data using real-time quantitative PCR and the 2(-Delta Delta C(T)) Method. Methods 25: 402-408.

18) Lowry OH, Rosebrough NJ, Farr AL, Randall RJ. 1951. Protein measurement with the Folin phenol reagent. J Biol Chem 193: 265-275.

19) Honma K, Mochizuki K, Goda T. 2007. Carbohydrate/fat ratio in the diet alters histone acetylation on the sucraseisomaltase gene and its expression in mouse small intes- 
tine. Biochem Biophys Res Commun 357: 1124-1129.

20) Iizuka K, Bruick RK, Liang G, Horton JD, Uyeda K. 2004. Deficiency of carbohydrate response element-binding protein (ChREBP) reduces lipogenesis as well as glycolysis. Proc Natl Acad Sci USA 101: 7281-7286.

21) Dentin R, Pegorier JP, Benhamed F, Foufelle F, Ferre P, Fauveau V, Magnuson MA, Girard J, Postic C. 2004. Hepatic glucokinase is required for the synergistic action of ChREBP and SREBP-1c on glycolytic and lipogenic gene expression. J Biol Chem 279: 20314-20326.

22) Shimano H. 2001. Sterol regulatory element-binding proteins (SREBPs): transcriptional regulators of lipid synthetic genes. Prog Lipid Res 40: 439-452.

23) Lu M, Shyy JY. 2006. Sterol regulatory element-binding protein 1 is negatively modulated by PKA phosphorylation. Am J Physiol Cell Physiol 290: C1477-C1486.

24) Hirano Y, Murata S, Tanaka K, Shimizu M, Sato R. 2003. Sterol regulatory element-binding proteins are negatively regulated through SUMO-1 modification independent of the ubiquitin/26 S proteasome pathway. J Biol Chem 278: 16809-16819.

25) Sakiyama H, Wynn RM, Lee WR, Fukasawa M, Mizuguchi H, Gardner KH, Repa JJ, Uyeda K. 2008. Regulation of nuclear import/export of carbohydrate response element-binding protein (ChREBP): interaction of an alpha-helix of ChREBP with the 14-3-3 proteins and regulation by phosphorylation. J Biol Chem 283:
24899-24908.

26) Rufo C, Teran-Garcia M, Nakamura MT, Koo SH, Towle HC, Clarke SD. 2001. Involvement of a unique carbohydrate-responsive factor in the glucose regulation of rat liver fatty-acid synthase gene transcription. J Biol Chem 276: 21969-21975.

27) Latasa MJ, Moon YS, Kim KH, Sul HS. 2000. Nutritional regulation of the fatty acid synthase promoter in vivo: sterol regulatory element binding protein functions through an upstream region containing a sterol regulatory element. Proc Natl Acad Sci USA 97: 10619-10624.

28) Oliner JD, Andresen JM, Hansen SK, Zhou S, Tjian R. 1996. SREBP transcriptional activity is mediated through an interaction with the CREB-binding protein. Genes Dev 10: 2903-2911.

29) Burke SJ, Collier JJ, Scott DK. 2009. cAMP opposes the glucose-mediated induction of the L-PK gene by preventing the recruitment of a complex containing ChREBP, HNF4alpha, and CBP. FASEB J 23: 2855-2865.

30) Lee DY, Hayes JJ, Pruss D, Wolffe AP. 1993. A positive role for histone acetylation in transcription factor access to nucleosomal DNA. Cell 72: 73-84.

31) Rousseau V, Becker DJ, Ongemba LN, Rahier J, Henquin JC, Brichard SM. 1997. Developmental and nutritional changes of ob and PPAR gamma 2 gene expression in rat white adipose tissue. Biochem J 321: 451-456. 